\title{
Analysis of pharmaceutical adulterants in plant food supplements by UHPLC-MS/MS
}

\author{
Paula Paíga a , Manuela J.E. Rodrigues a,b ${ }^{\text {a }}$ Manuela Correia ${ }^{\mathrm{a}, *}$, Joana S. Amaral ${ }^{\mathrm{b}, \mathrm{c}}$, \\ M. Beatriz P.P. Oliveira ${ }^{c}$, Cristina Delerue-Matos ${ }^{\mathrm{a}}$ \\ a REQUIMTE/LAQV, Instituto Superior de Engenharia do Instituto Politécnico do Porto, Rua Dr. António Bernardino de Almeida, 431, 4249-015 Porto, Portugal \\ ${ }^{\mathrm{b}}$ ESTiG, Instituto Politécnico de Bragança, Campus de Sta. Apolónia, 5300-253 Bragança, Portugal \\ c REQUIMTE, Departamento de Ciências Químicas, Faculdade de Farmácia, Universidade do Porto, Rua de Jorge Viterbo Ferreira, 228, 4050-313 Porto, Portugal
}

Keywords:

Plant food supplements

Pharmaceuticals

QuEChERS

Ultra-high performance liquid chromatography

Mass spectrometry

\begin{abstract}
A B S T R A C T
A method based on the Quick, Easy, Cheap, Effective, Rugged, and Safe (QuEChERS) extraction and ultra-high performance liquid chromatography coupled to tandem mass spectrometry (UHPLC-MS/MS) was successfully developed and validated for the analysis of 26 pharmaceutical compounds belonging to different therapeutic classes (anorexics, stimulants, anxiolytics, antidepressants and laxatives), which are all prone to be illegally added into weight-loss plant food supplements (PFS) for their pharmacological activity. Internal standard calibration with six isotopically labelled compounds rendered good linearity in the range of 5 to $1000 \mu \mathrm{g} / \mathrm{l}$, depending on the compound, and good sensitivity with limits of quantification in the range of $0.02-9.80 \mu \mathrm{g} / \mathrm{l}$. Recoveries were assessed for all the 16 samples analysed and were found between $70 \%$ and $120 \%$ for over $90 \%$ of the analytes. The average recovery value was $90.8 \%$, for the different studied matrices (liquids, liquid ampoules, tablets and capsules), with RSD values lower than $10 \%$ for all forms. The changes introduced to the QuEChERS procedure maintained the good performance characteristics of the extraction method while preserving the chromatographic system for the introduction of unwanted matrix compounds. Synephrine was the only compound detected and quantified in one sample, but at a very low concentration $(768 \mu \mathrm{g} / \mathrm{l})$ and its presence may be due to the plant extracts used in the formulation, as synephrine is known to be a natural constituent of Citrus aurantium amara. Despite none of the 16 evaluated samples were found to be adulterated by the illegal addition of the drugs included in this work, the developed methodology can be very useful for monitoring the adulteration of weight-loss PFS.
\end{abstract}

\section{Introduction}

Over the last few years, the consumption of plant food supplements (PFS) has been growing globally (Egan et al., 2011). Different factors have been pointed out to explain the commercial success of PFS, including a rising mistrust in pharmaceutical drugs, a higher demand for plant products and alternative therapies, and a rising tendency for self-medication (Egan et al., 2011; Vargas-Murga et al., 2011). Moreover, because PFS have plants or plant extracts as ingredients, they are often marketed as being "natural" products, which are generally perceived by many consumers as being safe and "healthier" than conventional pharmaceutical drugs (Rocha et al., 2016). Although several medicinal plants are frequently included in the formulation of PFS, these products are legally considered as foods both in the European Union (EU) and the United States of America (USA), under Directive 2002/46/EC (European Commission, 2002) and the Dietary Supplement Health and Education Act (DSHEA), respectively.
Therefore, both in the EU and USA, PFS do not require any safety assessment prior to their commercialization, with the responsibility for food safety issues relying on food business operators (Silano et al., 2011).

Among the several problems that may affect the safety of PFS, adulteration by the illegal addition of pharmaceutical drugs represents a public health concern of major importance. Over the last years, an increasing number of tainted PFS has been reported by the Food and Drug Administration (FDA) and by the European Rapid Alert System on Food and Feed (RASFF), with PFS marketed for enhancing sexual performance and for losing weight being the most frequent targets of adulteration (Rocha et al., 2016).

Since overweight currently affects millions of individuals worldwide, weight-loss products are undoubtedly one of the most popular type of PFS, particularly in the Western societies where slim figures are generally promoted, either for healthy or aesthetic motives. Weight-loss PFS are frequently advertised as products providing rapid slimming effects, thus representing easy solutions to lose weight compared to changes in eating behaviour and lifestyle/exercising. To promote their effectiveness and increase sales, unscrupulous producers 
can dope PFS with pharmaceutical drugs to provide for quick results in order to satisfy consumer's expectations. The adulterant drugs most frequently associated with weight-loss PFS are anorexics derived from amphetamines, including several substances previously used as medicines for the treatment of overweight and obesity, such as sibutramine (Meridia ${ }^{\circledR}$ and Reductil ${ }^{\circledR}$ ), fenfluramine (Ponderax ${ }^{\circledR}$ ) and rimonabant (Acomplia ${ }^{\circledR}$ ). The use of these drugs is currently banned by the FDA and the European Medicines Agency (EMA) due to potential risks of severe side effects, such as cardiovascular events. The use of other amphetamine-like anorexics, such as amfepramone and fenproporex, has also been reported since they are able to induce appetite loss, increase satiety and reduce intestinal fat absorption. According to Carvalho et al. (2011), other substances from different pharmaceutical classes, such as stimulants, anxiolytics, antidepressants and laxatives, are also prone to be illegally added to PFS. Besides anorexics, undeclared stimulants, including ephedrine, synephrine and methamphetamine, can be added to weight-loss PFS as they increase thermogenesis and induce loss of appetite. On the other hand, anxiolytics, such as benzodiazepines, can be added to mask the stimulating/euphoria effects of amphetaminederived anorexics and stimulants, and simultaneously contribute to diminishing anxiety, which is characteristically present in many obese patients (Carvalho et al., 2011). Moreover, it has been demonstrated that obesity and depression have a bidirectional relationship, meaning that obesity increases the risk of depression, especially in women, as well as depression increases the risk of overweight and obesity (Luppino et al., 2010). Therefore, antidepressants are also prone to be illegally added to weight-loss supplements, as reported by Cohen (2009) who described a case report of a 38-years old man using diet pills imported into the USA that were found to be adulterated with fenproporex and fluoxetine, after an occupational urine control positive for amphetamine. Finally, due to its pharmacological activity, the presence of laxatives has also been frequently reported in public notifications from the FDA and RASFF, in particular phenolphthalein, a drug used over a century to treat constipation but withdrawn from market in 1997 due to carcinogenicity concerns (Coogan et al., 2000).

Presently, hyphenated techniques, namely liquid chromatography coupled to tandem mass spectrometry (LC-MS/MS) are considered techniques of choice for the determination and quantification of pharmaceutical drugs in PFS, both because of the complexity of the matrix and due to its high selectivity and sensitivity (Liang et al., 2006; Vaclavik et al., 2014a; Vaclavik et al., 2014b). At the same time, nowadays the trend goes toward the use of ultra-high performance liquid chromatography (UHPLC), which uses short, narrow bore columns, packed with particles with a lower diameter (sub-2 $\mu \mathrm{m}$ ), allowing for a faster analysis, better resolution and narrower peaks compared to conventional HPLC methodologies (Paíga et al., 2015).

Therefore, the aim of this work was to develop an analytical methodology using UHPLC-MS/MS for the quantification of 26 pharmaceutical drugs belonging to different therapeutic classes (anorexics, stimulants, anxiolytics, antidepressants and laxatives), which are all prone to be illegally added into weight-loss PFS for their pharmacological activity. Two anticonvulsants were also included in the study, namely topiramate, which is approved to be used with fentermine for long term weight-management, and zonisamide since a combination of this compound together with bupropion is currently under clinical trials to be used as a treatment for obesity (FDA, 2012; Ioannides-Demos et al., 2011). The Quick, Easy, Cheap, Effective, Rugged, and Safe (QuEChERS) method was used for sample extraction based on a modification of the method proposed by Vaclavik et al., 2014b.

\section{Material and Methods}

\subsection{Reagents and Materials}

Acetonitrile and methanol for LC-MS were supplied by J.T. Baker (Deventer, Netherlands). Ultra-pure water $\left(18.2 \mathrm{M} \Omega \mathrm{cm}^{-1}\right)$ was produced using a Simplicity 185 system (Millipore, Molsheim, France). All chromatographic solvents were filtered through a $0.22 \mu \mathrm{m}$ nylon membrane filter (Supelco, Bellefonte, PA, USA) using a vacuum pump (Dinko D-95, Barcelona, Spain) and degassed for $15 \mathrm{~min}$ in an ultrasonic bath (Sonorex Digital 10P, BANDELIN, Germany). Formic acid ( $\geq 95 \%$ ), ammonium formate $(\geq 99.9 \%)$, anhydrous magnesium sulphate $(\geq$ 99.5\%) and sodium chloride ( $\geq 99.5 \%$ ) were purchased from Sigma-Aldrich (St. Louis, MO, USA). QuEChERS ( $4 \mathrm{~g} \mathrm{MgSO}_{4}$ and $1 \mathrm{~g} \mathrm{NaCl}$ ) were obtained from Agilent Technologies (Santa Clara, CA, USA).

All pharmaceutical standards were of high purity grade $(\geq 98.5 \%)$. Clobenzorex hydrochloride, fenfluramine hydrochloride, rimonabant, sibutramine hydrochloride, synephrine, and zonisamide were purchased from LGC (Middlesex, UK). Alprazolam, amfepramone hydrochloride, bupropion hydrochloride, D-cathine hydrochloride, diazepam, (+)-ephedrine hydrochloride, fentermine hydrochloride, lorazepam, mazindol, D,L-methamphetamine hydrochloride, D,Lnorephedrine hydrochloride, and topiramate were purchased from Lipomed AG (Arlesheim, Switzerland).

Topiramate-d12 in methanol solution was purchased from LGC (Middlesex, UK), diazepam-d5 and D,L-methamphetamine-d5 hydrochloride were acquired from Lipomed AG (Arlesheim, Switzerland). Carbamazepine- $d 10$, diazepam- $d 5$, fluoxetine- $d 5$, D,L-methamphetamine- $d 5$ and venlafaxine- $d 6$ were the isotopically labelled compounds used as internal standards in electrospray ionization (ESI) (+) whereas topiramate- $d 12$ was used in ESI ( - ) analysis.

Both individual stock standard and isotopically labelled internal standard solutions (at a concentration of $1000 \mathrm{mg} / \mathrm{l}$ ) were prepared on a weight basis in methanol. Working standard solutions containing all pharmaceuticals were prepared in acetonitrile-ultra-pure water $(5: 95, v / v)$ by mixing appropriate amounts of the stock solutions. These solutions were prepared before each analytical run.

\subsection{Samples}

Sixteen PFS samples were purchased from pharmacy stores, internet vendors or supplied by their producers. Most of the PFS were intended for weight loss purposes and two were St. John's wort based PFS. The analysed samples were in the form of capsules, liquids, ampoules, and tablets. A detailed description of the PFS samples is given in Table S1 (Supplementary material). The solid PFS were thoroughly homogenized before analysis.

\subsection{Sample Preparation}

A modification of the QuEChERS method proposed by Vaclavik et al (2014b) was used for sample extraction. The capsules were opened and their content homogenized while tablets were homogenized using a mortar and pestle.

An aliquot of $0.50 \pm 0.01 \mathrm{~g}$ of homogenized sample, in the case of tablets and capsules, or $5 \mathrm{ml}$, in the case of liquids, were measured into a $50 \mathrm{ml}$ polypropylene (PP) centrifuge tube. For recovery studies, spiking solution was added, the mixture was vortexed and rested for $30 \mathrm{~min}$. Then, $10 \mathrm{ml}$ (for solid samples) or $5 \mathrm{ml}$ (for liquid samples) of water containing $0.1 \%$ formic acid were added, vortexed for 1 min and incubated for $30 \mathrm{~min}$ under ambient conditions. Afterwards, $10 \mathrm{ml}$ of acetonitrile were added, vortexed for $1 \mathrm{~min}$ and shaken for $30 \mathrm{~min}$ at $100 \mathrm{rpm}$ in an orbital shaker AO-400 (Bunsen S.A., Madrid, Spain). Then, $4 \mathrm{~g}$ of anhydrous $\mathrm{MgSO}_{4}$ and $1 \mathrm{~g}$ of $\mathrm{NaCl}$ were added to the tube. The sample was vortexed for $1 \mathrm{~min}$ and centrifuged for $7 \mathrm{~min}$ at 1448g. An aliquot of $1 \mathrm{ml}$ of the acetonitrile extract was evaporated to dryness, re-dissolved in $1 \mathrm{ml}$ of acetonitrile:water $(80: 20 \%, \mathrm{v} / \mathrm{v})$, vortexed and filtered through a $0.22 \mu \mathrm{m}$ PTFE filter. $500 \mu \mathrm{l}$ of the extract were diluted with $1 \mathrm{ml}$ of acetonitrile:water $(10: 90 \%, \mathrm{v} / \mathrm{v})$ and left for $1 \mathrm{~h}$ in the refrigerator. If precipitation occurs, the mixture is centrifuged for 7 min at $1448 \mathrm{~g}$, filtered through a $0.22 \mu \mathrm{m}$ PTFE and analysed by UHPLC-MS/MS. Isotopically labelled compounds were added to 
standard solutions and sample extracts in order to obtain the following concentrations: carbamazepine-d10: $15 \mu \mathrm{g} / \mathrm{l}$; diazepam-d5: $60 \mu \mathrm{g} / \mathrm{l}$; fluoxetine-d5: $15 \mu \mathrm{g} / \mathrm{l}$; D,L-methamphetamine-d5: $100 \mu \mathrm{g} / \mathrm{l}$; topiramated12: $100 \mu \mathrm{g} / \mathrm{l}$ and venlafaxine-d6: $30 \mu \mathrm{g} / \mathrm{l}$.

\subsection{UHPLC-MS/MS Analysis}

Analysis was carried out on a UHPLC-MS/MS system consisting of a Shimadzu Nexera UHPLC system (Shimadzu Corporation, Kyoto, Japan) equipped with two solvent delivery modules LC-30 AD, a column oven CTO-20 AC, and an auto-sampler SIL-30 AC, coupled to a Shimadzu LCMS-8030 triple-quadrupole mass spectrometer (Shimadzu Corporation, Kyoto, Japan) operated in the electrospray ionization (ESI) mode. The system was controlled by a CBM-20A module. Lab Solutions software (Shimadzu Corporation, Kyoto, Japan) was used for control and data processing.

Chromatographic separation was achieved in a Kinetex C18 column $(150 \times 2.6 \mathrm{~mm} ; 1.7 \mu \mathrm{m}$ particle size $)$ (Phenomenex, USA). The injection volume was $5 \mu \mathrm{l}$ and column oven was set at $30^{\circ} \mathrm{C}$. The auto-sampler was operated at $4{ }^{\circ} \mathrm{C}$ and the needle was rinsed before and after sample aspiration using acetonitrile:methanol:propanol $(1: 1: 1, \mathrm{v} / \mathrm{v} / \mathrm{v})$.

In order to optimize the chromatographic separation and sensitivity of the studied analytes, different mobile phases and additives were tested. Acetonitrile was used as organic phase, while non-buffer ultra-pure water, $5 \mathrm{mM}$ ammonium acetate ( $\mathrm{pH} 4$ ) buffer solution, and $0.1 \%$ formic acid solution were evaluated as aqueous phases. Once the mobile phase composition was established, the elution mode (isocratic or gradient), as well as the flow rate were optimized with the aim to improve chromatographic resolution and peak shapes, and simultaneously to reduce total analysis time.

Two different gradient programs were used, one for ESI $(+)$ and the other for ESI $(-)$ modes. The optimized ESI $(+)$ mobile phase consisted of ultra-pure water containing $0.1 \%$ formic acid (eluent $A$ ) and acetonitrile (eluent $B$ ). The gradient elution was performed as follows: $0-1$ min eluent B 5\%; 1-6.50 min eluent B 5\%-100\%; 6.50-7.50 min eluent B 100\%; 7.50-8.50 min eluent B 100\%-5\%; column equilibration $8.5-$ $11 \mathrm{~min}$ eluent B $5 \%$ (flow rate $0.3 \mathrm{ml} \mathrm{min}^{-1}$ ). The ESI $(-$ ) mobile phase consisted of ultra-pure water (eluent A) and acetonitrile (eluent B), and the gradient elution was as follows: 0-5.50 min eluent B 10\%100\%; 5.50-6.50 min eluent B 100\%-10\%; column equilibration $6.5-$ 9 min eluent B 10\% (flow rate $0.3 \mathrm{ml} \mathrm{min}^{-1}$ ).

MS settings were analyte-specific and were optimized by direct injection of individual standard solutions $(10 \mathrm{mg} / \mathrm{l})$. The mass spectrometer was operated in multiple reaction monitoring mode (MRM) and two MRM transitions were monitored for each compound, being the most intense used as quantifier and the second one as qualifier. A dwell time of $15 \mathrm{~ms}$ was used for all compounds in the positive mode and $100 \mathrm{~ms}$ for the compounds in the negative mode.

Source-dependent parameters were also optimized by direct injection, using a standard mixture solution $(10 \mathrm{mg} / \mathrm{l})$, and were as follows: nebulizing gas (nitrogen) and drying gas (nitrogen) at a flow rate of 2.6 and $15.01 \mathrm{~min}^{-1}$, respectively; interface voltage was set at $5.0 \mathrm{kV}$; desolvation temperature was $300{ }^{\circ} \mathrm{C}$, and heat block temperature was $425^{\circ} \mathrm{C}$. Argon was used as the collision induced dissociation gas (CID) at a pressure of $230 \mathrm{kPa}$. Optimization was performed based on the sum of the areas of all peaks obtained within the specified variable ranges tested (interface voltage (IV): $0.2-5.0 \mathrm{kV}$; nebulizing gas flow: 0.5-3.0 $1 \mathrm{~min}^{-1}$; drying gas flow: $10-201 \mathrm{~min}^{-1}$; desolvation line temperature: $200-300^{\circ} \mathrm{C}$, and heat block temperature: $200-500{ }^{\circ} \mathrm{C}$ ).

\subsection{Validation of the Method}

The method was validated through the estimation of the linearity, detection (LOD) and quantification limits (LOQ), repeatability and reproducibility, extraction recoveries, and matrix effects.
Calibration curves were obtained by linear regression analysis over the established concentration levels in the range of 5 to $1000 \mu \mathrm{g} / \mathrm{l}$, depending on the compound. Quantification of the target analytes was performed by the internal standard approach. LODs and LOQs were calculated by the software as the minimum detectable amount of analyte with a signal-to-noise $(\mathrm{S} / \mathrm{N})$ of 3 and 10 , respectively.

The intra-day precision was determined by analysis of a $100 \mu \mathrm{g} / \mathrm{l}$ mixed standard solution six times within a single day, and the interday precision was assessed by the analysis of the standard solution on three consecutive days. Precision was expressed as the relative standard deviation (RSD) of the replicates.

Matrix effects were assessed in order to evaluate, for each analyte, the degree of ion suppression or enhancement. Matrix effects were calculated as the ratio of the peak area of a standard spiked in a blank matrix and the same standard concentration prepared in solvent (the mobile phase). A value of $100 \%$ indicates that there is no matrix effect, while values higher than $100 \%$ reflect ion enhancement and values lower than $100 \%$ ion suppression.

Recoveries were calculated as the ratio between the concentrations calculated using internal standard calibration, and the initial spiking levels. Recovery tests were performed at a single fortification level, for all the different samples analysed. For each recovery experiment, blanks (unspiked samples) were previously analysed for the presence of the analytes. With the exception of one sample, none of the studied compounds was determined in the blanks.

\section{Results and Discussion}

\subsection{Optimization of UHPLC-MS/MS Parameters}

The identification of precursor and product ions, and preliminary optimization of the instrument settings were performed using individual compound solutions prepared in acetonitrile $(100 \mathrm{mg} / \mathrm{l})$. Mass transitions and MS/MS parameters were optimized in order to attain the best specificity and sensitivity. Analyte's MRM transitions were monitored in the positive and negative ESI modes. Most of the compounds included in this study formed ions under positive mode ESI conditions. The majority of the analytes (23) provided intense $[\mathrm{M}+\mathrm{H}]^{+}$ions (Table 1), while zonisamide, phenolphthalein, topiramate, and topiramate-d12 were analysed in the negative ionization (ESI) mode, as $[\mathrm{M}-\mathrm{H}]^{-}$ions (Table 1). For most compounds, two MRM transitions from the ionized molecule of the target compound were monitored. The most abundant product ion was used for quantification and the second transition was used as qualifier. For the isotopically labelled internal standards only one MRM was monitored since they are not likely to be found in the PFS samples. Of the 23 analytes studied, 11 compounds have been previously analysed by Vaclavik et al. (2014b) under ESI (+) in a Q Exactive quadrupole-orbitrap mass spectrometer. In our study, using a triple quadrupole MS/MS equipment, those compounds were also analysed in ESI $(+)$ with the exception of topiramate, which was analysed under ESI $(-)$, and they all produced at least one or two of the ions listed by Vaclavik et al. (2014b). Product ion mass spectra for the different compounds are shown in Figs. S.1 and S.2 (Supplementary materials). Once the most appropriate ions have been selected, ionization parameters including drying and nebulizing gas flow rates, heat block and desolvation temperatures and interface voltage were optimized as described in materials and methods section, since they are known to be key parameters to obtain higher sensitivity. Figs. S.3 to S.7 (Supplementary materials) present the data used for optimization of the source-dependent parameters regarding all analytes with the exception of the antidepressants and diazepam, for which optimization data was obtained in a previous work (Santos et al., 2016).

When analysing complex matrices, such as PFS, a chromatographic step preceding the ionization and mass analysis of the analyte molecules is of major importance since it enables the separation of compounds that can interfere or supress the signals of the analytes of 
Table 1

Optimized MS/MS conditions for the selected compounds analysed in the positive and negative electrospray ionization (ESI) mode.

\begin{tabular}{|c|c|c|c|c|c|c|c|c|c|c|c|c|}
\hline \multirow[t]{2}{*}{ Number } & \multirow[t]{2}{*}{ Compound } & \multicolumn{2}{|c|}{ Precursor ion } & \multicolumn{4}{|c|}{ Product 1} & \multicolumn{4}{|c|}{ Product 2} & \multirow[t]{2}{*}{ Ion ratic } \\
\hline & & & & $m / z$ & $\begin{array}{l}\text { Q1 } \\
\text { Pre Bias } \\
(\mathrm{V})\end{array}$ & $\mathrm{CE}$ & $\begin{array}{l}\text { Q3 } \\
\text { Pre Bias } \\
(\mathrm{V})\end{array}$ & $m / z$ & $\begin{array}{l}\text { Q1 } \\
\text { Pre Bias } \\
(\mathrm{V})\end{array}$ & $\mathrm{CE}$ & $\begin{array}{l}\text { Q3 } \\
\text { Pre Bias } \\
(\mathrm{V})\end{array}$ & \\
\hline \multicolumn{13}{|l|}{ ESI $(+)$} \\
\hline 1 & Alprazolam & 309.10 & {$[\mathrm{M}+\mathrm{H}]^{+}$} & 281.05 & -14 & -27 & -19 & 204.95 & -14 & -44 & -22 & 1.22 \\
\hline 2 & Amfepramone & 205.50 & {$[\mathrm{M}+\mathrm{H}]^{+}$} & 105.10 & -30 & -30 & -20 & 100.15 & -30 & -25 & -19 & 1.14 \\
\hline 3 & Bupropion & 239.50 & {$[\mathrm{M}+\mathrm{H}]^{+}$} & 183.85 & -30 & -17 & -21 & 131.15 & -30 & -18 & -13 & 1.11 \\
\hline 4 & Carbamazepine & 236.95 & {$[\mathrm{M}+\mathrm{H}]^{+}$} & 194.10 & -21 & -20 & -13 & 193.10 & -21 & -35 & -13 & 4.91 \\
\hline 5 & Cathine & 151.70 & {$[\mathrm{M}+\mathrm{H}]^{+}$} & 134.10 & -16 & -14 & -13 & 117.10 & -16 & -21 & -23 & 2.33 \\
\hline 6 & Citalopram & 324.85 & {$[\mathrm{M}+\mathrm{H}]^{+}$} & 109.20 & -30 & -26 & -22 & 262.20 & -30 & -19 & -18 & 3.77 \\
\hline 7 & Clobenzorex & 259.50 & {$[\mathrm{M}+\mathrm{H}]^{+}$} & 91.10 & -30 & -30 & -17 & 119.15 & -30 & -16 & -12 & 2.29 \\
\hline 8 & Diazepam & 284.75 & {$[\mathrm{M}+\mathrm{H}]^{+}$} & 154.05 & -27 & -29 & -15 & 193.05 & -27 & -33 & -13 & 1.20 \\
\hline 9 & Ephedrine & 165.50 & {$[\mathrm{M}+\mathrm{H}]^{+}$} & 148.15 & -30 & -19 & -15 & 91.10 & -30 & -33 & -17 & 3.35 \\
\hline 10 & Fenfluramine & 231.50 & {$[\mathrm{M}+\mathrm{H}]^{+}$} & 159.05 & -30 & -23 & -16 & 109.15 & -30 & -45 & -21 & 3.05 \\
\hline 11 & Fentermine & 149.50 & {$[\mathrm{M}+\mathrm{H}]^{+}$} & 91.10 & -28 & -21 & -18 & 65.05 & -28 & -42 & -12 & 5.48 \\
\hline 12 & Fluoxetine & 310.25 & {$[\mathrm{M}+\mathrm{H}]^{+}$} & 44.25 & -11 & -14 & -16 & 148.15 & -11 & -10 & -15 & 13.17 \\
\hline 13 & Lorazepam & 320.90 & {$[\mathrm{M}+\mathrm{H}]^{+}$} & 274.90 & -16 & -22 & -19 & 302.90 & -16 & -17 & -21 & 2.01 \\
\hline 14 & Mazindol & 285.10 & {$[\mathrm{M}+\mathrm{H}]^{+}$} & 43.70 & -13 & -30 & -30 & 18.05 & -13 & -55 & -19 & 18.70 \\
\hline 15 & Methamphetamine & 149.50 & {$[\mathrm{M}+\mathrm{H}]^{+}$} & 91.10 & -30 & -21 & -17 & 119.10 & -30 & -16 & -23 & 4.62 \\
\hline 16 & Norephedrine & 151.60 & {$[\mathrm{M}+\mathrm{H}]^{+}$} & 134.10 & -30 & -15 & -14 & 117.15 & -30 & -21 & -11 & 2.28 \\
\hline 17 & Paroxetine & 330.00 & {$[\mathrm{M}+\mathrm{H}]^{+}$} & 70.20 & -22 & -33 & -13 & 44.15 & -22 & -26 & -17 & 1.54 \\
\hline 18 & Rimonabant & 462.50 & {$[\mathrm{M}+\mathrm{H}]^{+}$} & 362.90 & -30 & -29 & -25 & 84.10 & -30 & -27 & -16 & 3.42 \\
\hline 19 & Sertraline & 306.15 & {$[\mathrm{M}+\mathrm{H}]^{+}$} & 275.10 & -28 & -13 & -19 & 159.05 & -28 & -29 & -16 & 0.89 \\
\hline 20 & Sibutramine & 279.50 & {$[\mathrm{M}+\mathrm{H}]^{+}$} & 125.10 & -30 & -24 & -12 & 139.10 & -30 & -17 & -14 & 1.81 \\
\hline 21 & Synephrine & 167.70 & {$[\mathrm{M}+\mathrm{H}]^{+}$} & 150.10 & -16 & -12 & -15 & 91.10 & -16 & -23 & -18 & 4.09 \\
\hline 22 & Trazodone & 371.85 & {$[\mathrm{M}+\mathrm{H}]^{+}$} & 176.10 & -30 & -26 & -18 & 148.15 & -30 & -36 & -15 & 1.21 \\
\hline 23 & Venlafaxine & 277.90 & {$[\mathrm{M}+\mathrm{H}]^{+}$} & 58.20 & -30 & -21 & -10 & 260.30 & -30 & -13 & -18 & 5.66 \\
\hline 24 & Carbamazepine- $d 10$ & 247.15 & {$[\mathrm{M}+\mathrm{H}]^{+}$} & 204.15 & -23 & -22 & -14 & & & & & \\
\hline 25 & Diazepam-d5 & 290.10 & {$[\mathrm{M}+\mathrm{H}]^{+}$} & 154.05 & -13 & -29 & -10 & & & & & \\
\hline 26 & Fluoxetine-d5 & 315.15 & {$[\mathrm{M}+\mathrm{H}]^{+}$} & 44.25 & -11 & -14 & -16 & & & & & \\
\hline 27 & D,L-Methamphetamine- $d 5$ & 154.50 & {$[\mathrm{M}+\mathrm{H}]^{+}$} & 92.10 & -30 & -21 & -18 & & & & & \\
\hline 28 & Venlafaxine- $d 6$ & 283.50 & {$[\mathrm{M}+\mathrm{H}]^{+}$} & 64.05 & -30 & -21 & -11 & & & & & \\
\hline \multicolumn{13}{|l|}{$\mathrm{ESI}(-)$} \\
\hline 29 & Phenolphthalein & 317.10 & {$[\mathrm{M}-\mathrm{H}]^{-}$} & 93.05 & 20 & 13 & 18 & 273.00 & 20 & 23 & 20 & 6.85 \\
\hline 30 & Topiramate & 338.10 & {$[\mathrm{M}-\mathrm{H}]^{-}$} & 77.85 & 23 & 27 & 15 & 96.05 & 23 & 25 & 19 & 6.82 \\
\hline 31 & Zonisamide & 211.10 & {$[\mathrm{M}-\mathrm{H}]^{-}$} & 118.95 & 13 & 15 & 24 & 147.05 & 13 & 10 & 30 & 1.66 \\
\hline 32 & Topiramate-d12 & 350.20 & {$[\mathrm{M}-\mathrm{H}]^{-}$} & 77.90 & 22 & 31 & 15 & & & & & \\
\hline
\end{tabular}

CE - Collision energy.

interest and, when standards are available, allows for the comparison of retention times. Therefore, despite the mass selectivity of the detector, baseline separation of the analytes is always preferred in LC-MS (Vaclavik et al., 2014a). In this work, chromatographic conditions were optimized regarding mobile phase composition and gradient to improve the resolution of compounds and peak shape in the shortest analysis time. Different mobile phases comprising several combinations of organic solvents and water were tested using isocratic and gradient elution. Of the several mobile phases tested in ESI $(+)$, including acetonitrile, water, $0.1 \%$ formic acid solution, and $5 \mathrm{mM}$ ammonium acetate buffer $(\mathrm{pH}=4)$, best chromatographic performance was achieved using $0.1 \%$ formic acid and acetonitrile, which were consequently chosen as mobile phase. The effect of the initial organic solvent percentage was tested in the range of $5-30 \%$, and the best results were obtained using the lowest value. In ESI $(+)$, the retention times of the $28 \mathrm{com}-$ pounds ( 23 analytes and 5 isotopically labelled compounds used as internal standards) were $<8 \mathrm{~min}$, with a total run time of $12 \mathrm{~min}$ (Fig. 1). In ESI (-), water and acetonitrile were used in gradient mode, allowing the analysis of 3 compounds and one internal standard in $<5$ min (Fig. 2).

\subsection{QuEChERS Extraction}

As discussed by Vaclavik et al. (2014a) in a recent review paper on the MS analysis of pharmaceutical adulterants in PFS, analytes' extraction is mostly accomplished using organic solvents, namely, methanol and acetonitrile. Homogenized solid samples are usually extracted by means of shaking and/or sonication while liquid samples are frequently diluted with the solvent. These procedures are considered simple and relatively rapid, however in complex matrices, such as PFS, have the disadvantage of frequently co-isolate high amounts of matrix components that can potentially interfere with the detection of target analytes and cause severe matrix effects in MS analysis (Vaclavik et al., 2014a; Vaclavik et al., 2014b). Although QuEChERS extraction can overpass such inconvenient, this approach has not been frequently used in PFS analysis. The exception is the work performed by the same group of authors, where QuEChERS were employed for the analysis of 96 pharmaceuticals, plant toxins, and other plant secondary metabolites in PFS. In the present work, the QuEChERS method used for sample extraction was based on a modification of the reported method (Vaclavik et al., 2014b), which included the analysis of the acetonitrile layer, directly or after dilution with pure acetonitrile, using 10 to 10,000 dilution factors aiming to eliminate matrix effects (Vaclavik et al., 2014b). However, our experimental conditions did not allow the use of such high dilution factors. Additionally, for many samples, large amounts of sample components were transferred to the acetonitrile extract, that were not soluble in the initial composition of the mobile phase used in the gradient ( $5 \%$ of acetonitrile), and precipitate in the chromatographic column. Therefore, modifications to the sample extraction procedure were introduced in order to avoid this situation, namely an aliquot of $1 \mathrm{ml}$ of the acetonitrile layer was evaporated to dryness and re-dissolved in $1 \mathrm{ml}$ of acetonitrile:water ( $80: 20 \%, \mathrm{v} / \mathrm{v})$, since a high percentage of organic solvent is needed to increase the solubility of the analytes in the solution. Afterwards, $500 \mu \mathrm{l}$ of the extract were combined with $1 \mathrm{ml}$ of acetonitrile:water $(10: 90 \%, \mathrm{v} / \mathrm{v})$ in order to increase the water content of the extract before analysis, and also to assess if precipitation 


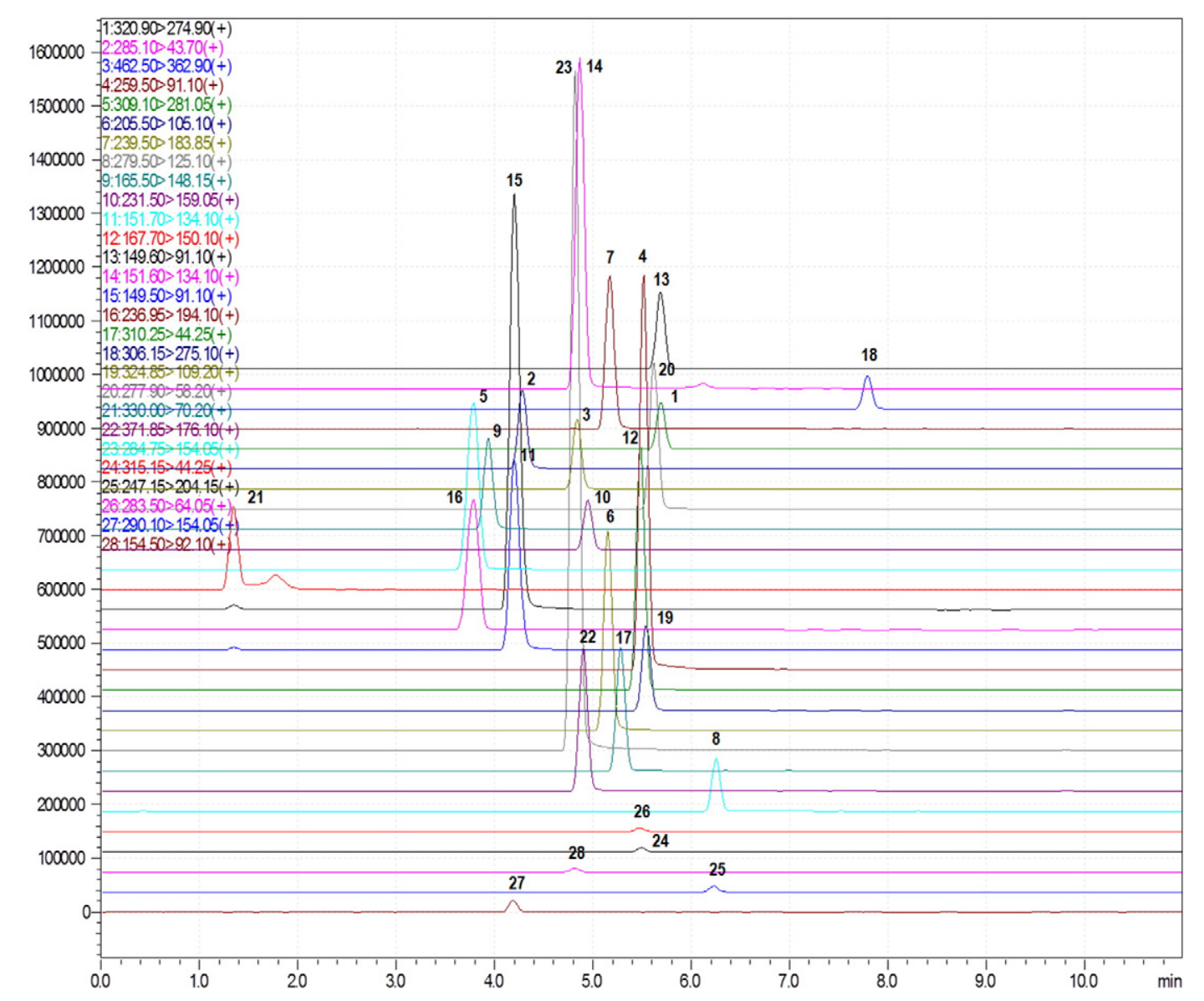

Fig. 1. Overlay chromatograms of the compounds analysed in ESI ( + ) mode (For peak identification refer to Table 1).

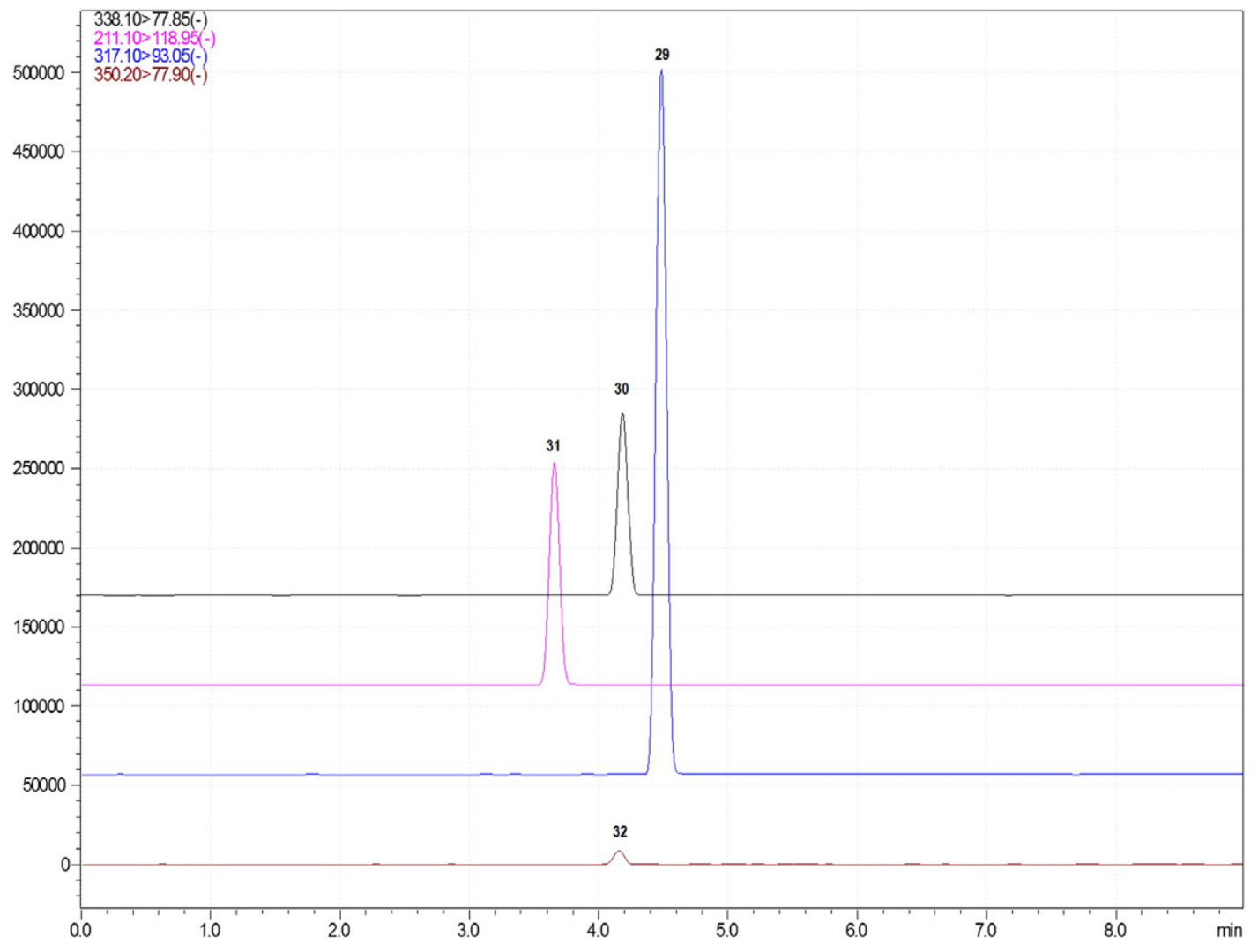

Fig. 2. Overlay chromatograms of the compounds analysed in ESI (-) mode (For peak identification refer to Table 1). 
occurs for this new solvent composition. This modification allowed the analysis of the different types of samples (liquids, tablets and capsules) with good recoveries, as will be discussed in the next section, while avoiding the introduction of unwanted sample components in the chromatographic column and MS detector.

\subsection{Method Validation}

The validation parameters of the UHPLC-MS/MS method are presented in Table 2. Under the optimized conditions, standard mixtures were analysed to obtain calibration curves based on the linear regression analysis of the peak area versus concentration, using appropriate internal standards. Calibration curves with nine calibration levels in the range $5-1000 \mu \mathrm{g} / \mathrm{l}$ were tested for all the compounds. Depending on the analyte, some levels were excluded in order to improve linearity. Calibration parameters (slope, intercept, and coefficient of determination) were automatically obtained from the software. With the exception of trazodone (0.9984) and clobenzorex (0.9979), all the determination coefficients $\left(\mathrm{R}^{2}\right)$ were higher than 0.999 (Table 2). Chromatograms of individual standard solutions of topiramate and sibutramine as well as the corresponding calibration curves are shown in Figs. S.8 to S.11 (Supplementary materials), as examples.

LODs and LOQs were in the range 0.01-2.94 $\mu \mathrm{g} / \mathrm{l}$ and $0.02-9.80 \mu \mathrm{g} / \mathrm{l}$, respectively, showing an adequate sensitivity to detect possible adulterations by the illegal addition of these drugs to PFS.

Intra-day precision (expressed as coefficient of variation) ranged from $0.9 \%$ to $6.4 \%$, for carbamazepine- $d 10$ and fluoxetine- $d 5$, respectively, with an average value of $3.3 \%$. Inter-day precision was in the range of 0.5 to $11.4 \%$, for clobenzorex and synephrine, respectively, with a mean value of $5.9 \%$.

Matrix effects were assessed using a mixed standard solution which was evaporated to dryness and re-dissolved in matrix extract. Matrix effects, estimated as the ratio of the obtained peak area and the one for the standard in solvent are shown on Table 3. The lowest value was observed for citalopram in a capsule sample (60.2\%), and the highest was found for carbamazepine in a liquid sample (145.0\%).

Recovery results for all the matrices analysed are presented in Table 4. QuEChERS recovery was calculated as the ratio of the estimated concentrations obtained for the fortified samples and the theoretical amount used for spiking. The lowest recovery was obtained for citalopram in a capsule sample (54.9\%) and the highest was found for amfepramone in a liquid sample (130.5\%). Considering all the samples, acceptable recoveries between $70 \%$ and $120 \%$ were obtained for over $90 \%$ of the analytes. The average recovery value obtained for all the matrices and analytes was $90.8 \%$, which indicates a good performance of the method for the different studied matrices (liquids, liquid ampoules, tablets and capsules), with RSD values lower than $10 \%$ for all forms. The lowest recovery values, in the range 54.9-69.0\%, were obtained only for $8.56 \%$ of the combinations of analytes/samples tested and were mainly related to cathine, norephedrine, and synephrine, which are some of the most water soluble compounds studied.

\subsection{Application to Real Samples}

Although previous studies have been reported on the detection of pharmaceutical substances in PFS marketed for weight-loss, most are restricted to the evaluation of a few drugs, mainly comprising anorexics and stimulants (Cianchino et al., 2008; Reeuwijk et al., 2014; Zeng et al., 2016). Other works refer to PFS in general and, therefore, include a great number of substances of different classes including analgesics, anti-diabetics, aphrodisiac drugs, blood pressure and cholesterol-lowering drugs, anti-inflammatory drugs and plant toxins, among others (Bogusz et al., 2006; Chen et al., 2009; Johansson et al., 2014; Kim et al., 2009; Vaclavik et al., 2014b), which are of few interest when specifically considering weight-loss PFS. In this work, as a more effective approach toward the detection of adulterated PFS marketed for weight loss, the substances of interest were selected on the basis of their suitability to be used as adulterants for their pharmacological activities. Therefore, different drugs including anorexics, stimulants,

Table 2

Validation parameters of the developed UHPLC-MS/MS method for the compounds analysed in the ESI (+) and ESI $(-)$ modes listed by retention time.

\begin{tabular}{|c|c|c|c|c|c|c|c|}
\hline Compound & $\operatorname{tr}(\min )$ & IS & Calibration equation & $\begin{array}{l}\text { Calibration range } \\
(\mu \mathrm{g} / \mathrm{l})\end{array}$ & $\mathrm{R}^{2}$ & $\begin{array}{l}\text { LOD } \\
(\mu \mathrm{g} / \mathrm{l})\end{array}$ & $\begin{array}{l}\text { LOQ } \\
(\mu \mathrm{g} / \mathrm{l})\end{array}$ \\
\hline \multicolumn{8}{|l|}{ ESI $(+)$} \\
\hline Synephrine & 1.344 & M & $Y=0.758789 X+0.0229380$ & $5-250(n=6)$ & 0.9994 & 0.53 & 1.75 \\
\hline Cathine & 3.786 & M & $Y=1.54181 X-0.0249693$ & $5-1000(\mathrm{n}=9)$ & 0.9992 & 0.76 & 2.54 \\
\hline Norephedrine & 3.786 & M & $\mathrm{Y}=1.25304 \mathrm{X}-0.0232795$ & $5-250(n=7)$ & 0.9997 & 0.46 & 1.54 \\
\hline Methamphetamine & 3.786 & M & $Y=1.90389 X+0.0597238$ & $5-250(\mathrm{n}=7)$ & 0.9995 & 0.23 & 0.77 \\
\hline Ephedrine & 3.939 & M & $Y=0.806934 X+0.286717$ & $5-250(n=7)$ & 0.9993 & 0.49 & 1.62 \\
\hline Phentermine & 4.200 & M & $Y=4.49850 X+0.104529$ & $5-250(n=6)$ & 0.9994 & 0.19 & 0.63 \\
\hline Amfepramone & 4.282 & M & $Y=0.869667 X+0.0231053$ & $5-250(n=7)$ & 0.9985 & 0.41 & 1.35 \\
\hline Venlafaxine & 4.822 & $\mathrm{~V}$ & $Y=6.89422 X-0.129923$ & $5-750(\mathrm{n}=8)$ & 0.9999 & 0.08 & 0.28 \\
\hline Bupropion & 4.840 & M & $\mathrm{Y}=0.589020 \mathrm{X}+0.0147755$ & $5-250(n=6)$ & 0.9995 & 0.39 & 1.29 \\
\hline Mazindol & 4.864 & $\mathrm{M}$ & $\mathrm{Y}=3.68487 \mathrm{X}-0.0225639$ & $5-750(\mathrm{n}=9)$ & 0.9995 & 2.94 & 9.8 \\
\hline Trazodone & 4.900 & $\mathrm{~F}$ & $\mathrm{Y}=0.832830 \mathrm{X}+0.711928$ & $5-250(n=7)$ & 0.9984 & 0.10 & 0.32 \\
\hline Fenfluramine & 4.950 & M & $Y=0.477972 X-0.0314184$ & $5-1000(\mathrm{n}=9)$ & 0.9999 & 1.97 & 4.95 \\
\hline Citalopram & 5.154 & $\mathrm{~F}$ & $\mathrm{Y}=1.20743 \mathrm{X}+0.117510$ & $5-500(\mathrm{n}=8)$ & 0.9999 & 0.08 & 0.25 \\
\hline Clobenzorex & 5.172 & M & $\mathrm{Y}=1.30241 \mathrm{X}-0.0165424$ & $5-250(n=7)$ & 0.9979 & 0.45 & 1.51 \\
\hline Paroxetine & 5.282 & $\mathrm{~F}$ & $Y=0.614295 X-0.0715692$ & $5-500(\mathrm{n}=8)$ & 0.9988 & 0.23 & 0.77 \\
\hline Fluoxetine & 5.486 & $\mathrm{~F}$ & $Y=1.03079 X+0.137943$ & $5-1000(\mathrm{n}=9)$ & 0.9996 & 0.05 & 0.17 \\
\hline Carbamazepine & 5.511 & $\mathrm{C}$ & $Y=1.62729 X+0.0403706$ & $5-1000(\mathrm{n}=9)$ & 0.9998 & 0.11 & 0.35 \\
\hline Sertraline & 5.546 & $\mathrm{~F}$ & $\mathrm{Y}=0.482933 \mathrm{X}+0.113437$ & $5-500(\mathrm{n}=8)$ & 0.9998 & 0.01 & 0.04 \\
\hline Sibutramine & 5.628 & M & $\mathrm{Y}=1.42670 \mathrm{X}-0.0844654$ & $5-1000(n=10)$ & 0.9992 & 0.51 & 1.7 \\
\hline Lorazepam & 5.684 & M & $Y=0.292740 X-0.0178989$ & $5-250(n=7)$ & 0.9994 & 0.17 & 0.58 \\
\hline Alprazolam & 5.687 & $\mathrm{M}$ & $Y=0.417668 X-0.0391036$ & $5-1000(n=10)$ & 0.9996 & 0.23 & 0.76 \\
\hline Diazepam & 6.249 & $\mathrm{D}$ & $Y=0.612050 X+0.0304583$ & $5-250(n=7)$ & 0.9993 & 0.10 & 0.32 \\
\hline Rimonabant & 7.789 & M & $Y=0.360945 X-0.00218738$ & $5-750(\mathrm{n}=9)$ & 0.9998 & 0.04 & 0.12 \\
\hline \multicolumn{8}{|l|}{$\operatorname{ESI}(-)$} \\
\hline Zonisamide & 3.658 & $\mathrm{~T}$ & $Y=1.79851 X+0.117548$ & $25-750(\mathrm{n}=7)$ & 0.9998 & 0.13 & 0.44 \\
\hline Topiramate & 4.185 & $\mathrm{~T}$ & $\mathrm{Y}=1.34519 \mathrm{X}-0.0106935$ & $5-1000(n=10)$ & 0.9998 & 0.12 & 0.42 \\
\hline Phenolphthalein & 4.483 & $\mathrm{~T}$ & $\mathrm{Y}=7.12323 \mathrm{X}+0.553430$ & $10-500(n=7)$ & 0.9995 & 0.01 & 0.02 \\
\hline
\end{tabular}

IS - Internal standard; C: Carbamazepine-d10; D: Diazepam-d5; F: Fluoxetine-d5; M: D,L-Methamphetamine-d5; T: Topiramate-d12; V: Venlafaxine-d6. 
Table 3

Matrix effect (\%) for the different analytes and samples at a concentration of $250 \mu \mathrm{g} / \mathrm{l}$.

\begin{tabular}{|c|c|c|c|c|c|c|c|c|c|c|c|c|c|c|c|c|c|}
\hline \multirow[t]{2}{*}{ Compound } & \multicolumn{7}{|c|}{ Liquid samples } & \multicolumn{4}{|c|}{ Liquid ampoule samples } & \multicolumn{2}{|l|}{ Tablet } & \multicolumn{3}{|c|}{ Capsule samples } & \multirow{2}{*}{$\begin{array}{l}\text { Mean } \\
(\%)\end{array}$} \\
\hline & PFS2 & PFS3 & PFS4 & PFS14 & PFS15 & PFS16 & PFS5 & PFS6 & PFS11 & PFS12 & PFS13 & PFS7 & PFS1 & PFS8 & PFS9 & PFS10 & \\
\hline \multicolumn{18}{|l|}{$\mathrm{ESI}(+)$} \\
\hline Alprazolam & 133.3 & 127.6 & 112.6 & 128.2 & 130.1 & 132.4 & 115.4 & 113.0 & 111.5 & 106.2 & 122.1 & 109.2 & 130.0 & 128.9 & 114.7 & 132.5 & 121.7 \\
\hline Amfepramone & 69.2 & 72.3 & 76.8 & 70.5 & 67.3 & 62.8 & 72.2 & 64.6 & 72.5 & 71.3 & 71.8 & 75.0 & 80.7 & 66.8 & 77.6 & 80.3 & 72.0 \\
\hline Bupropion & 85.7 & 78.9 & 104.7 & 88.4 & 93.8 & 98.2 & 92.0 & 86.0 & 104.0 & 94.0 & 88.6 & 97.1 & 83.5 & 90.1 & 94.6 & 105.1 & 92.8 \\
\hline Carbamazepine & 145.1 & 132.5 & 132.4 & 140.2 & 145.0 & 142.7 & 133.9 & 129.6 & 135.2 & 131.2 & 144.0 & 137.5 & 133.9 & 126.3 & 137.1 & 141.6 & 136.8 \\
\hline Cathine & 116.2 & 103.4 & 107.9 & 107.0 & 110.1 & 104.9 & 113.1 & 116.4 & 117.0 & 121.9 & 100.0 & 100.2 & 84.4 & 105.9 & 116.1 & 116.5 & 108.8 \\
\hline Citalopram & 72.1 & 62.3 & 65.3 & 64.5 & 63.0 & 60.4 & 69.2 & 73.3 & 87.2 & 98.3 & 66.5 & 76.9 & 60.2 & 133.2 & 90.8 & 70.4 & 75.9 \\
\hline Clobenzorex & 93.2 & 81.1 & 86.3 & 82.7 & 95.7 & 93.8 & 79.3 & 76.5 & 119.0 & 116.5 & 83.5 & 107.1 & 100.9 & 110.9 & 120.8 & 91.1 & 96.2 \\
\hline Diazepam & 128.2 & 127.6 & 131.1 & 128.4 & 137.9 & 126.3 & 117.6 & 117.1 & 126.6 & 119.6 & 139.8 & 127.3 & 136.3 & 129.1 & 127.1 & 119.8 & 127.5 \\
\hline Ephedrine & 120.8 & 72.2 & 112.3 & 105.6 & 108.8 & 111.0 & 98.7 & 79.6 & 124.5 & 121.3 & 102.0 & 127.6 & 94.7 & 103.6 & 115.3 & 113.5 & 107.0 \\
\hline Fenfluramine & 86.3 & 92.0 & 114.5 & 93.5 & 88.6 & 91.3 & 81.1 & 83.2 & 119.2 & 105.5 & 99.9 & 83.5 & 93.3 & 87.4 & 107.4 & 113.2 & 96.2 \\
\hline Fluoxetine & 110.0 & 111.7 & 103.6 & 105.0 & 95.9 & 88.6 & 97.8 & 101.2 & 127.3 & 123.9 & 105.1 & 105.6 & 82.1 & 109.4 & 122.9 & 116.3 & 106.7 \\
\hline Lorazepam & 124.4 & 115.4 & 118.4 & 108.5 & 115.5 & 102.8 & 117.3 & 117.2 & 118.7 & 119.6 & 116.9 & 118.8 & 107.3 & 103.7 & 117.4 & 126.5 & 115.5 \\
\hline Mazindol & 104.1 & 98.2 & 107.8 & 97.3 & 95.8 & 91.7 & 105.9 & 107.1 & 118.5 & 97.9 & 95.7 & 119.7 & 83.1 & 115.5 & 116.4 & 121.7 & 104.8 \\
\hline Methamphetamine & 86.1 & 109.4 & 85.1 & 84.9 & 92.8 & 99.8 & 95.2 & 86.9 & 101.3 & 94.5 & 84.6 & 104.8 & 108.1 & 96.5 & 106.0 & 104.7 & 96.3 \\
\hline Norephedrine & 107.8 & 92.6 & 105.0 & 96.3 & 93.9 & 92.6 & 100.8 & 102.3 & 101.9 & 107.4 & 93.0 & 91.7 & 89.7 & 94.3 & 102.2 & 106.5 & 98.6 \\
\hline Paroxetine & 83.3 & 87.7 & 81.2 & 87.4 & 81.7 & 78.3 & 88.2 & 100.3 & 94.2 & 95.5 & 90.8 & 77.9 & 65.1 & 95.6 & 91.8 & 101.9 & 87.5 \\
\hline Phentermine & 79.6 & 99.0 & 88.8 & 72.2 & 90.5 & 96.0 & 88.0 & 80.6 & 89.9 & 88.1 & 81.3 & 99.0 & 102.1 & 82.3 & 100.7 & 101.2 & 90.0 \\
\hline Rimonabant & 110.0 & 129.6 & 126.0 & 114.5 & 125.8 & 127.0 & 108.6 & 111.0 & 109.9 & 116.3 & 123.8 & 119.3 & 60.6 & 120.4 & 112.1 & 119.6 & 114.7 \\
\hline Sertraline & 108.7 & 97.5 & 98.4 & 97.8 & 95.1 & 80.1 & 109.0 & 112.6 & 117.3 & 120.4 & 96.2 & 105.7 & 84.7 & 88.1 & 113.6 & 116.2 & 102.6 \\
\hline Subitramine & 89.4 & 96.7 & 106.6 & 100.8 & 96.3 & 95.3 & 89.8 & 97.5 & 97.7 & 99.3 & 108.0 & 97.8 & 71.2 & 93.7 & 94.6 & 97.6 & 95.8 \\
\hline Synephrine & 72.1 & 89.8 & 97.9 & 111.7 & 134.7 & 74.9 & 135.6 & 93.0 & 79.2 & 137.1 & 129.1 & 69.9 & 80.6 & 74.4 & 88.4 & 115.3 & 99.0 \\
\hline Trazodone & 114.4 & 101.5 & 122.8 & 104.3 & 122.3 & 109.3 & 101.4 & 100.6 & 112.7 & 105.2 & 112.5 & 125.4 & 122.1 & 128.3 & 133.4 & 104.1 & 94.1 \\
\hline Venlafaxine & 108.9 & 106.7 & 102.7 & 112.2 & 120.8 & 116.9 & 100.7 & 107.4 & 109.1 & 90.2 & 113.8 & 127.5 & 107.7 & 137.4 & 109.7 & 102.6 & 113.8 \\
\hline \multicolumn{18}{|l|}{ ESI $(-)$} \\
\hline Phenolphthaleine & 61.1 & 87.5 & 58.1 & 87.5 & 64.1 & 73.2 & 75.7 & 75.0 & 62.7 & 88.2 & 82.3 & 75.1 & 76.5 & 75.3 & 67.6 & 86.3 & 74.8 \\
\hline Topiramate & 114.6 & 114.5 & 92.7 & 125.1 & 103.5 & 108.4 & 111.7 & 121.9 & 109.1 & 111.5 & 120.3 & 114.2 & 72.0 & 110.2 & 120.4 & 125.6 & 111.0 \\
\hline Zonisamide & 106.2 & 138.7 & 97.6 & 139.7 & 123.3 & 121.4 & 133.1 & 139.1 & 97.1 & 90.4 & 134.5 & 69.8 & 61.7 & 62.7 & 86.4 & 137.6 & 108.7 \\
\hline
\end{tabular}

antidepressants, anxiolytics, a laxative and two anticonvulsants whose use is associated with weight-loss, were selected. As far as we know, this is the first study reporting a methodology for the detection of some compounds (citalopram, fentermine, trazodone, venlafaxine and zonisamide) in PFS, and other compounds (alprazolam, diazepam, lorazepam and cathine) in PFS specifically marketed for weight-loss purposes.

After optimization and validation, the method was successfully applied to the analysis of sixteen PFS samples comprising different pharmaceutical forms, namely liquids, ampoules, capsules and tablets.

Table 4

Recovery values (\%) obtained in different samples at a fortification level of $15 \mathrm{mg} / \mathrm{kg}$ for solid samples and $1.5 \mathrm{mg} / \mathrm{l}$ for liquid samples.

\begin{tabular}{|c|c|c|c|c|c|c|c|c|c|c|c|c|c|c|c|c|c|}
\hline \multirow[t]{2}{*}{ Compound } & \multicolumn{7}{|c|}{ Liquid samples } & \multicolumn{4}{|c|}{ Liquid ampoule samples } & \multicolumn{2}{|l|}{ Tablet } & \multicolumn{3}{|c|}{ Capsule samples } & \multirow[t]{2}{*}{ Mean } \\
\hline & PFS2 & PFS3 & PFS4 & PFS14 & PFS15 & PFS16 & PFS5 & PFS6 & PFS11 & PFS12 & PFS13 & PFS7 & PFS1 & PFS8 & PFS9 & PFS10 & \\
\hline \multicolumn{18}{|l|}{$\mathrm{ESI}(+)$} \\
\hline Alprazolam & 80.2 & 97.2 & 77.9 & 79.6 & 69.0 & 69.8 & 85.0 & 89.5 & 84.8 & 100.1 & 81.0 & 82.3 & 84.9 & 90.2 & 81.6 & 80.1 & 83.3 \\
\hline Amfepramone & 122.1 & 114.6 & 115.0 & 126.1 & 123.3 & 130.5 & 110.1 & 123.2 & 121.6 & 128.0 & 120.1 & 106.3 & 95.1 & 114.4 & 107.8 & 115.3 & 117.1 \\
\hline Bupropion & 110.6 & 109.2 & 109.1 & 110.3 & 115.3 & 98.1 & 109.6 & 113.1 & 105.1 & 116.0 & 112.2 & 117.0 & 92.4 & 114.3 & 121.8 & 111.9 & 110.4 \\
\hline Carbamazepine & 80.9 & 85.1 & 87.8 & 72.1 & 82.2 & 80.2 & 81.5 & 89.0 & 81.2 & 84.1 & 81.5 & 86.0 & 93.8 & 105.9 & 74.4 & 103.5 & 85.6 \\
\hline Cathine & 67.7 & 86.6 & 79.9 & 89.5 & 72.8 & 83.2 & 67.4 & 71.9 & 68.3 & 75.5 & 98.1 & 80.1 & 80.2 & 66.4 & 72.9 & 101.2 & 78.9 \\
\hline Citalopram & 76.1 & 96.6 & 100.2 & 109.1 & 104.4 & 98.7 & 83.6 & 84.6 & 63.9 & 77.6 & 100.9 & 87.7 & 99.2 & 54.9 & 81.9 & 96.1 & 88.4 \\
\hline Clobenzorex & 74.8 & 94.6 & 93.2 & 83.8 & 84.1 & 96.3 & 83.5 & 86.4 & 79.1 & 82.4 & 99.8 & 93.8 & 88.3 & 89.3 & 79.2 & 94.8 & 87.7 \\
\hline Diazepam & 95.6 & 97.2 & 86.3 & 99.5 & 91.6 & 88.8 & 101.4 & 109.7 & 92.5 & 110.7 & 83.6 & 91.5 & 83.5 & 74.5 & 86.7 & 103.8 & 93.6 \\
\hline Ephedrine & 67.5 & 92.5 & 91.5 & 93.5 & 79.3 & 98.9 & 87.6 & 102.2 & 79.5 & 71.0 & 88.1 & 82.7 & 77.6 & 92.2 & 73.8 & 112.4 & 86.9 \\
\hline Fenfluramine & 103.8 & 123.2 & 94.6 & 114.4 & 111.8 & 94.9 & 106.6 & 114.3 & 88.4 & 106.2 & 102.3 & 108.0 & 95.8 & 101.5 & 97.5 & 113.4 & 104.8 \\
\hline Fluoxetine & 84.0 & 80.3 & 92.9 & 85.9 & 105.7 & 85.9 & 84.9 & 89.6 & 76.2 & 87.0 & 84.1 & 81.5 & 99.8 & 108.8 & 87.9 & 99.9 & 89.7 \\
\hline Lorazepam & 82.7 & 83.6 & 84.2 & 83.6 & 95.3 & 92.6 & 89.6 & 85.6 & 79.4 & 87.2 & 82.8 & 85.2 & 81.1 & 86.5 & 78.3 & 118.6 & 87.3 \\
\hline Mazindol & 79.1 & 108.1 & 88.1 & 107.8 & 100.9 & 105.8 & 89.2 & 84.0 & 78.6 & 88.4 & 99.0 & 99.7 & 97.8 & 95.7 & 83.8 & 81.2 & 93.0 \\
\hline Methamphetamine & 100.9 & 96.7 & 110.9 & 113.5 & 96.0 & 104.3 & 98.5 & 106.9 & 101.7 & 107.4 & 111.6 & 91.3 & 91.4 & 79.8 & 91.3 & 116.7 & 101.2 \\
\hline Norephedrine & 61.4 & 82.8 & 76.1 & 87.2 & 73.4 & 79.9 & 67.0 & 70.6 & 72.3 & 73.9 & 88.1 & 72.8 & 74.8 & 67.1 & 74.8 & 95.8 & 76.1 \\
\hline Paroxetine & 92.1 & 94.9 & 97.2 & 93.3 & 103.0 & 95.9 & 86.1 & 84.5 & 85.0 & 84.6 & 83.5 & 84.2 & 103.3 & 71.8 & 75.1 & 106.9 & 90.1 \\
\hline Phentermine & 94.8 & 93.7 & 93.0 & 112.8 & 93.6 & 84.8 & 103.0 & 104.0 & 100.5 & 100.6 & 100.5 & 86.8 & 83.6 & 81.5 & 83.3 & 112.7 & 95.6 \\
\hline Rimonabant & 105.1 & 96.0 & 90.2 & 103.7 & 100.8 & 87.0 & 98.2 & 117.8 & 95.0 & 100.9 & 103.7 & 83.3 & 96.9 & 80.9 & 103.8 & 122.8 & 99.1 \\
\hline Sertraline & 71.4 & 107.9 & 88.5 & 99.7 & 86.5 & 94.5 & 80.5 & 79.3 & 76.1 & 76.5 & 96.4 & 74.7 & 88.9 & 84.4 & 66.5 & 96.7 & 85.5 \\
\hline Subitramine & 97.7 & 102.5 & 99.5 & 101.0 & 111.2 & 97.2 & 100.1 & 93.9 & 93.1 & 99.7 & 88.9 & 93.9 & 116.2 & 89.6 & 120.5 & 119.8 & 101.6 \\
\hline Synephrine & 67.9 & 83.3 & 105.4 & 67.3 & 72.7 & 67.6 & 60.9 & 65.3 & 70.4 & 64.3 & 61.5 & 67.8 & 68.2 & 75.3 & 61.4 & 64.3 & 70.2 \\
\hline Trazodone & 82.6 & 79.7 & 88.8 & 83.3 & 82.2 & 86.5 & 90.4 & 85.9 & 88.4 & 79.6 & 90.1 & 86.0 & 88.1 & 78.6 & 103.0 & 109.4 & 87.7 \\
\hline Venlafaxine & 87.9 & 100.2 & 100.9 & 82.4 & 85.6 & 82.8 & 100.5 & 95.8 & 97.4 & 95.2 & 86.0 & 88.3 & 93.8 & 87.8 & 97.4 & 130.1 & 94.5 \\
\hline \multicolumn{18}{|l|}{$\operatorname{ESI}(-)$} \\
\hline Phenolphthaleine & 81.9 & 87.0 & 79.7 & 90.9 & 85.8 & 86.1 & 88.7 & 91.0 & 72.0 & 83.6 & 87.6 & 85.6 & 84.7 & 76.4 & 82.4 & 106.2 & 85.6 \\
\hline Topiramate & 78.4 & 86.9 & 87.0 & 85.4 & 96.6 & 80.4 & 86.4 & 80.8 & 80.1 & 86.6 & 88.2 & 73.0 & 81.5 & 75.3 & 70.2 & 108.9 & 84.1 \\
\hline Zonisamide & 78.0 & 62.1 & 83.0 & 63.0 & 81.6 & 81.1 & 81.0 & 72.7 & 80.4 & 91.2 & 88.0 & 81.5 & 90.9 & 67.8 & 81.5 & 105.1 & 80.6 \\
\hline
\end{tabular}


With the exception of synephrine, none of the other 25 drugs was detected in any of the evaluated samples. The presence of synephrine was confirmed in one sample, codified as sample PFS12, at a concentration of $768 \mu \mathrm{g} / \mathrm{l}$ (Fig. 3). This may be related to the composition of the sample, as indicated in the label (Table S.1), since $135 \mathrm{mg}$ of bitter orange extract (Citrus aurantium amara - button and flower) were declared in the formulation, and synephrine is known to be a natural constituent of this plant (Di Lorenzo et al., 2014). Bitter orange (Citrus aurantium $\mathrm{L}$.), or the respective extract, is an ingredient frequently used in food supplements aimed at reducing body weight due to its composition in bioactive amines with adrenergic activity, of which synephrine is the most representative. Both bitter orange and synephrine are permitted in food supplements, but several countries have established limits for the content of active amines, in particular of synephrine, for which the dosage should not exceed $30 \mathrm{mg} /$ day ( $\mathrm{Di}$ Lorenzo et al., 2014). The determined content of synephrine, corresponding to $7.7 \mu \mathrm{g}$ per ampoule, is much below this limit. Considering the low content of this compound, its presence in the sample is most probably explained by the use of the plant extract and not by the addition of synephrine and therefore should not be considered neither as a fraud or mislabelling.

Compared to previous studies on PFS adulteration, the obtained results were identical to those of Choi et al. (2015) who also did not detect any of the 28 narcotic adulterants analysed in 47 dietary supplements purchased in South Korea. By the contrary, recently, Hachem et al. (2016) analysed 160 PFS marketed for weight-loss by using Proton NMR and found that 43 samples contained the anorexic sibutramine, 9 samples contained phenolphthalein, 23 samples a mixture of sibutramine and phenolphthalein, 12 samples sildenafil (a drug for erectile dysfunction), 4 samples the antidepressant fluoxetine, 1 sample the anorexic orlistat and 1 samples contained the anorexic lorcaserine. A high level of adulteration in weight-loss PFS was also described by Reeuwijk et al. (2014) which reported that 24 out of 50 PFS acquired in 2004 and 2010-2013 were adulterated with sibutramine,

\section{Sample PFS 12}
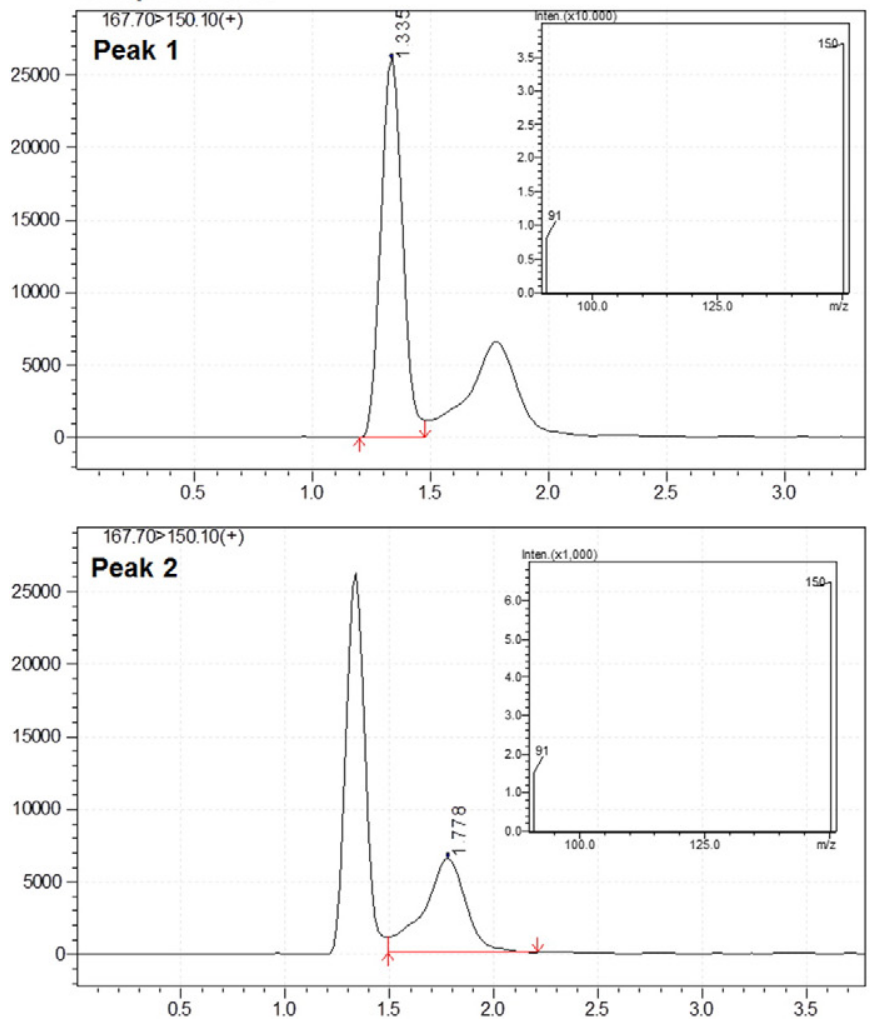

rimonabant, sildenafil and phenolphthalein and by Johansson et al. (2014) which detected different adulterants (sibutramine, orlistat, sildenafil, fluoxetine and/or yohimbine) in 21 out of 43 weigh-loss PFS. In both cases, the high level of adulterations found could be related to the sampling strategy since in the study of Reeuwijk et al. (2014) PFS were sampled by inspectors of the Netherlands Food and Consumer Product Safety Authority, which collected products based on experience, reports and alerts, and in the study of Johansson et al. (2014) samples were collected from the illegal market within projects performed together with the Swedish police and/or customs. Slightly lower levels of adulteration in weight-loss PFS were reported by Zeng et al. (2016), namely 119 samples out of 447, albeit samples also included PFS seized during enforcement operations. A significantly lower number of adulterated PFS (4 out of 106) was reported by Carvalho et al. (2011) when analysing weight-loss PFS sold by compounding pharmacies in Brazil.

\section{Conclusions}

A method based on QuEChERS extraction and UHPLC-MS/MS was successfully developed and validated for the analysis of 26 pharmaceutical compounds belonging to different therapeutic classes (anorexics, stimulants, anxiolytics, antidepressants and laxatives), which are all prone to be illegally added into weight-loss PFS for their pharmacological activity. Internal standard calibration with six isotopically labelled compounds rendered good linearity and sensitivity with LOQs in the range of $0.02-9.80 \mu \mathrm{g} / \mathrm{l}$. Matrix effects and recoveries were assessed for all the 16 samples analysed and were found between $70 \%$ and $120 \%$ for over $90 \%$ of the analytes. The changes introduced to the QuEChERS procedure maintained the good performance characteristics of the extraction method while preserving the chromatographic system for the introduction of unwanted matrix compounds. Synephrine was the only compound detected and quantified in one sample, but at a very low concentration ( $\left.768 \mu \mathrm{g} \mathrm{l}^{-1}\right)$ and its presence may be due to

Synephrine $250 \mu \mathrm{g} / \mathrm{L}$
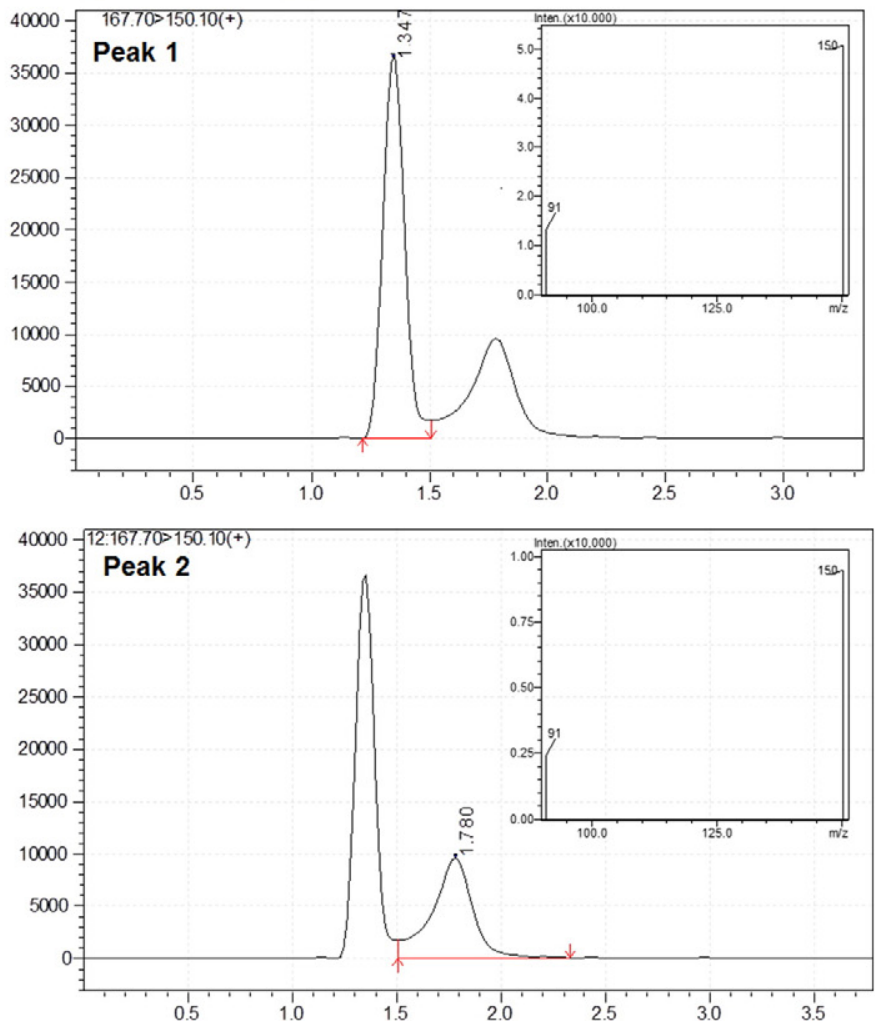

Fig. 3. Chromatograms of the PFS sample positive for synephrine (PFS12) and a synephrine standard solution (250 $\mu \mathrm{g} / \mathrm{l})$. 
the plant extracts used in the formulation, as synephrine is known to be a natural constituent of Citrus aurantium amara. Despite none of the 16 evaluated samples were found to be adulterated by the illegal addition of the drugs included in this work, the developed methodology can be very useful for monitoring the adulteration of weight-loss PFS.

\section{Conflict of interest}

All authors declare no conflict of interest.

\section{Acknowledgements}

This work received financial support from the European Union (FEDER funds through COMPETE) and National Funds (FCT, Fundação para a Ciência e a Tecnologia) through project EXPL/DTP-SAP/1438/ 2013 and Pest-C/EQB/LA0006/2013. To all financing sources the authors are greatly indebted. The authors also acknowledge the companies that gently supplied some of the samples.

\section{Appendix A. Supplementary Data}

Supplementary data to this article can be found online at http://dx. doi.org/10.1016/j.ejps.2016.12.024.

\section{References}

Bogusz, M.J., Hassan, H., Al-Enazi, E., Ibrahim, Z., Al-Tufail, M., 2006. Application of LC-ESIMS-MS for detection of synthetic adulterants in herbal remedies. J. Pharm. Biomed. Anal. 41, 554-564.

Carvalho, L.M., Martini, M., Moreira, A.P.L., Lima, A.P.S., Correia, D., Falcão, T., Garcia, S.C., Bairros, A.V., Nascimento, P.C., Bohrer, D., 2011. Presence of synthetic pharmaceuticals as adulterants in slimming phytotherapeutic formulations and their analytical determination. Forensic Sci. Int. 204, 6-12.

Chen, Y., Zhao, L., Lu, F., Yu, Y., Chai, Y., Wu, Y., 2009. Determination of synthetic drugs used to adulterate botanical dietary supplements using QTRAP LC-MS/MS. Food Addit. Contam. Part A 26, 595-603.

Choi, J.Y., Heo, S., Yoo, G.J., Park, S.-K., Yoon, C.-Y., Baek, S.Y., 2015. Development and validation of an LC-MS/MS method for the simultaneous analysis of 28 specific narcotic adulterants used in dietary supplements. Food Addit. Contam. Part A 32, 1029-1039.

Cianchino, V., Acosta, G., Ortega, C., Martínez, L.D., Gomez, M.R., 2008. Analysis of potential adulteration in herbal medicines and dietary supplements for the weight control by capillary electrophoresis. Food Chem. 108, 1075-1081.

Cohen, P.A., 2009. Imported fenproporex-based diet pills from Brazil: a report of two cases. J. Gen. Intern. Med. 24, 430-433.

Coogan, P.F., Rosenberg, L., Palmer, J.R., Strom, B.L., Zauber, A.G., Stolley, P.D., Shapiro, S., 2000. Phenolphthalein laxatives and risk of cancer. J. Natl. Cancer Inst. 92, 1943-1944.

Di Lorenzo, C., Dos Santos, A., Colombo, F., Moro, E., Dell'Agli, M., Restani, P., 2014. Development and validation of HPLC method to measure active amines in plant food supplements containing Citrus aurantium L. Food Control 46, 136-142.

Egan, B., Hodgkins, C., Shepherd, R., Timotijevic, L., Raats, M., 2011. An overview of consumer attitudes and beliefs about plant food supplements. Food Funct. 2, 747-752.
European Commission, 2002. Directive 2002/46/EC of the European Parliament and of the council of 10 June 2002 on the approximation of the laws of the Member States relating to food supplements. Off. J. Eur. Communities 183, 51-57.

FDA - Food and Drug Administration, 2012. FDA news release. FDA Approves Weight-management Drug Qsymia. http://www.fda.gov/NewsEvents/Newsroom/ PressAnnouncements/ucm312468.htm (accessed in May 2016).

Hachem, R., Assemat, G., Martins, N., Balayssac, S., Gilard, V., Martino, R., Malet-Martino, M., 2016. Proton NMR for detection, identification and quantification of adulterants in 160 herbal food supplements marketed for weight loss. J. Pharm. Biomed. Anal. 124, 34-47.

Ioannides-Demos, L.L., Piccenna, L., McNeil, J.J., 2011. Pharmacotherapies for obesity: past, current, and future therapies. J. Obes. 2011, 1-18.

Johansson, M., Fransson, D., Rundlof, T., Huynh, N.H., Arvidsson, T., 2014. A general analytical platform and strategy in search for illegal drugs. J. Pharm. Biomed. Anal. 100, 215-229.

Kim, S.H., Lee, J., Yoon, T., Choi, J., Choi, D., Kim, D., Kwon, S.W., 2009. Simultaneous determination of anti-diabetes/anti-obesity drugs by LC/PDA, and targeted analysis of sibutramine analog in dietary supplements by LC/MS/MS. Biomed. Chromatogr. 23, 1259-1265.

Liang, Q., Qu, J., Luo, G., Wang, Y., 2006. Rapid and reliable determination of illegal adulterant in herbal medicines and dietary supplements by LC/MS/MS. J. Pharm. Biomed. Anal. 40, 305-311.

Luppino, F.S., de Wit, L.M., Bouvy, P.F., Stijnen, T., Cuijpers, P., Penninx, B.W., Zitman, F.G., 2010. Overweight, obesity, and depression: a systematic review and meta-analysis of longitudinal studies. Arch. Gen. Psychiatry 67, 220-229.

Paíga, P., Lolić, A., Hellebuyck, F., Santos, L.H.M.L.M., Correia, M., Delerue-Matos, C., 2015. Development of a SPE-UHPLC-MS/MS methodology for the determination of nonsteroidal anti-inflammatory and analgesic pharmaceuticals in seawater. J. Pharm. Biomed. Anal. 106, 61-70.

Reeuwijk, N.M., Venhuis, B.J., de Kaste, D., Hoogenboom, R.L., Rietjens, I.M., Martena, M.J., 2014. Active pharmaceutical ingredients detected in herbal food supplements for weight loss sampled on the Dutch market. Food Addit. Contam. Part A 31, 1783-1793.

Rocha, T., Amaral, J.S., Oliveira, M.B.P.P., 2016. Adulteration of dietary supplements by the illegal addition of synthetic drugs: a review. Compr. Rev. Food Sci. Food Saf. 15, 43-62.

Santos, L.H.M.LM., Ramalhosa, MJ., Ferreira, M. Delerue-Matos, C. 2016. Development of a modified acetonitrile-based extraction procedure followed by ultra-high performance liquid chromatography-tandem mass spectrometry for the analysis of psychiatric drugs in sediments. J. Chromatogr. A 1437, 37-48.

Silano, V., Coppens, P., Larrañaga-Guetaria, A., Minghetti, P., Roth-Ehrang, R., 2011. Regulations applicable to plant food supplements and related products in the European Union. Food Funct. 2, 710-719.

Vaclavik, L., Krynitsky, A.J., Rader, J.I., 2014a. Mass spectrometric analysis of pharmaceutical adulterants in products labelled as botanical dietary supplements or herbal remedies: a review. Anal. Bioanal. Chem. 406, 6767-6790.

Vaclavik, L., Krynitsky, A.J., Rader, J.I., 2014b. Targeted analysis of multiple pharmaceuticals, plant toxins and other secondary metabolites in herbal dietary supplements by ultra-high performance liquid chromatography-quadrupole-orbital ion trap mass spectrometry. Anal. Chim. Acta 810, 45-60.

Vargas-Murga, L, Garcia-Alvarez, A., Roman-Viñas, B., Ngo, J., Ribas-Barba, L, Van den Berg, S.J.P.L., Williamson, G., Serra-Majem, L., 2011. Plant food supplement (PFS) market structure in EC member states, methods and techniques for the assessment of individual PFS intake. Food Funct. 2, 731-739.

Zeng, Y., Xu, Y., Kee, C.L., Low, M.Y., Ge, X., 2016. Analysis of 40 weight loss compounds adulterated in health supplements by liquid chromatography quadrupole linear ion trap mass spectrometry. Drug Test Anal. 8, 351-356. 